\title{
STUDI PERKIRAAN KEBUTUHAN ENERGI LISTRIK DI KOTA DUMAI SAMPAI TAHUN 2025 DENGAN METODA FUZZY LOGIC
}

\author{
Tri Handayani' ${ }^{1}$ Atmam $^{2}$, Masnur Putra Halilintar ${ }^{3}$ \\ 1,2,3 Program Studi Teknik Elektro, Fakultas Teknik, Universitas Lancang Kuning Pekanbaru. \\ Jl. Yos Sudarso Rumbai, Pekanbaru, Telp. (0761) 52324 \\ Email : triihd96@gmail.com, atmam@unilak.ac.id, masnur@unilak.ac.id
}

\begin{abstract}
ABSTRAK
Dalam proses perencanaan pengembangan sistem tenaga listrik diperlukan adanya suatu perkiraan kebutuhan tenaga listrik dimasa yang akan datang. Hasil perkiraan yang didapatkan bisa dijadikan bahan pertimbangan bagi pembuat kebijakan untuk merumuskan tindakan yang akan diambil untuk masa-masa mendatang. Hal ini bertujuan demi tercapainya optimalisasi dalam proses penyediaan energi listrik. Untuk optimalisasi penyediaan energi listrik di Kota Dumai, diperlukan suatu perkiraan kebutuhan energi listrik. Pada penelitian ini, metoda perkiraan yang digunakan adalah logika fuzzy. Perkiraan yang dilakukan bersifat jangka menengah, yaitu sampai tahun 2025. Perkiraan kebutuhan energi listrik jangka menengah umumnya mengacu pada statistik masa lalu dan atas dasar karakteristik konsumsi energi yang lalu. Karakteristik tersebut biasanya dipengaruhi oleh beberapa faktor, seperti jumlah penduduk, jumlah pelanggan listrik, PDRB. Metoda logika fuzzy ini menggunakan data histori/aktual yang diakumulasikan dalam beberapa periode waktu, yaitu dari tahun 2013 sampai 2017. Hasil perkiraan dengan menggunakan logika fuzzy menunjukkan bahwa konsumsi energi listrik di Kota Dumai setiap tahunnya memiliki rata-rata pertumbuhan sebesar 7,16\%. Pada tahun 2025 perkiraan konsumsi energi listrik menggunakan fuzzy sebesar $792 \mathrm{GWh}$, sedangkan perkiraan yang dilakukan oleh PLN, yaitu sebesar 866 GWh. Nilai kesalahan antara hasil perkiraan logika fuzzy dengan PLN pada tahun 2025 tersebut adalah sebesar $8,5 \%$.
\end{abstract}

Kata kunci : Perkiraan kebutuhan energi listrik, Logika fuzzy

\begin{abstract}
Planning for the development of an electric power system requires an estimate of electricity demand in the future. The result of the estimates obtained can be taken into consideration for policy makers to formulate actions taken for the future. This aims to achieve optimization in the process of providing electricity. To optimize the supply of electricity in the city of Dumai, an estimate of electricity needs is needed. In this study, the estimate method used is fuzzy logic. Estimates carried out are aimed for medium term, namely until 2025. Estimates of medium - term electrical energy requirements generally refer to past statistics are usually influenced by several factors such as population, number of electricity costumers, GDP (Gross Regional Domestic Product). This fuzzy logic method uses historical/actual data accumulated in several periods of time, form 2013 to 2017. The result of estimates using fuzzy logic show that electricity consumption in Dumai city has an annual growth rate of 7,16. In 2025 the estimated electricity consumption using fuzzy logic is 792 GWh; while estimates made by PLN (State Electricity Company) are 866 GWh. The error value between the estimated results of fuzzy logic and PLN in 2025 is $8,5 \%$.
\end{abstract}

Keywords : Estimates of electrical energy requirements, Fuzzy logic

\section{PENDAHULUAN}

Listrik merupakan salah satu bentuk energi yang sangat banyak dibutuhkan, makin tinggi tingkat perekonomian, dan semakin majunya teknologi maka kebutuhan energi listrik juga akan semakin tinggi. Dalam sistem kelistrikan, strategi perkiraan kebutuhan energi listrik sangat dibutuhkan untuk memperkirakan dengan tepat seberapa besar daya listrik yang akan dibutuhkan untuk melayani beban dan kebutuhan distribusi energi listrik. Untuk mengantisipasi kebutuhan energi listrik di Kota Dumai, diperlukan perkiraan yang tepat seberapa besar daya listrik yang dibutuhkan untuk melayani beban dan kebutuhan energi listrik dalam distribusi energi listrik. Perkiraan yang tidak tepat akan menyebabkan tidak cukupnya kapasitas daya yang akan disalurkan untuk memenuhi kebutuhan beban, 
sebaliknya jika perkiraan beban terlalu besar maka akan menyebabkan kelebihan kapasitas daya sehingga menyebabkan kerugian. Berdasarkan pertumbuhan jumlah penduduk, peningkatan pembangunan infrastruktur, pertumbuhan ekonomi dan ketersediaan energi listrik di kota Dumai, maka perlu dilakukan peramalan perencanaan penambahan pembangkit listrik yang baru, perluasan jaringan distribusi dan kebutuhan perencanaan penjadwalan pengoperasian pembangkit energi listrik, agar daya yang dibangkitkan sesuai dengan kebutuhan beban. Oleh karena itu, penulis menggunakan suatu metoda yang mampu memberikan hasil peramalan yang akurat untuk menanggulangi keterbatasan tersebut. Peramalan beban listrik dilakukan dengan menggunakan metoda logika fuzzy. Metoda fuzzy yang digunakan adalah metoda fuzzy Mamdani karena memiliki kemampuan meramal yang lebih baik dibandingkan dengan peramalan konvensional. Dimana inputnya berupa yaitu: pertumbuhan populasi jiwa, jumlah pelanggan, dan PDRB, kemudian dipetakan dalam suatu FIS (Fuzzy Inference System), dimana FIS mengevaluasi semua rule secara simultan untuk menghasilkan output berupa konsumsi energi listrik.

Tujuan dari penelitian ini adalah untuk untuk memperkirakan kebutuhan energi listrik kota Dumai sampai tahun 2025 dengan menggunakan metoda fuzzy logic. Batasan masalah dalam penilitian ini adalah sebagai berikut :

a. Beberapa data yang digunakan untuk menentukan perkiraan kebutuhan tenaga listrik adalah dalam hal :

1. Pertumbuhan Produk Domestik Regional Bruto (PDRB) pada pertumbuhan 5 tahun terakhir.

2. Pertumbuhan penduduk menggunakan rata - rata pertumbuhan 5 tahun terakhir.

b. Data histrori yang digunakan dari tahun 2013 dari PT. PLN (Persero) yang dipakai untuk menganalisa perkiraan energi listrik di Kota Dumai.

c. Metoda yang digunakan Fuzzy Mamdani.

d. Tidak ada perubahan radikal dalam 7 tahun yang akan datang sehingga menyebabkan pola pertumbuhan tenaga listrik sesuai dengan trend selama ini.

e. Penelitian ini tidak membahas pengembangan gardu induk maupun jaringan distribusi.

\section{METODE PENELITIAN}

Penyelesaian perkiraan kebutuhan energi listrik dalam penelitian ini, sistem fuzzy mamdani digunakan dengan 3 variabel input yaitu : jumlah penduduk, jumlah pelanggan dan PDRB yang akan diproses menggunakan metode mamdani. Selain menggunakan perhitungan metode mamdani dalam penelitian ini juga menerapkan aplikasi yang tersedia pada MATLAB. Hal ini akan dapat membantu dalam pengambilan keputusan berdasarkan visualisasi yang tersedia seperti rule, surface, dan fungsi keanggotaan.

\section{Bentuk Beban Listrik}

Tenaga listrik yang didistribusikan ke pelanggan (konsumen) digunakan sebagai sumber daya untuk bermacam-macam peralatan yang membutuhkan tenaga listrik sebagai sumber energinya. Peralatan tersebut umumnya bisa berupa lampu (penerangan), beban daya (untuk motor listrik), pemanas, dan sumber daya peralatan elektronik. Berdasarkan jenis konsumen energi listrik, secara garis besar, ragam beban dapat diklasifikasikan ke dalam [1] :

a. Beban rumah tangga, pada umumnya beban rumah tangga berupa lampu untuk penerangan, alat rumah tangga, seperti kipas angin, pemanas air, lemari es, penyejuk udara, mixer, oven, motor pompa air dan sebagainya. Beban rumah tangga biasanya memuncak pada malam hari.

b. Beban komersial, pada umumnya terdiri atas penerangan untuk reklame, kipas angin, penyejuk udara dan alat- alat listrik lainnya yang diperlukan untuk restoran. Beban hotel juga diklasifikasikan sebagai beban komersial (bisnis) begitu juga perkantoran. Beban ini secara drastis naik disiang hari untuk beban perkantoran dan pertokoan dan menurun diwaktu sore.

c. Beban industri, dibedakan dalam skala kecil dan skala besar. Untuk skala kecil banyak beroperasi disiang hari sedangkan industri besar sekarang ini banyak yang beroperasi sampai 24 jam.

d. Beban Fasilitas Umum, terdiri atas gedung pemerintahan, penerangan jalan umum dan pemakaian kepentingan sosial.

Pengklasifikasian ini sangat penting artinya bila kita melakukan analisa karakteristik beban untuk suatu sistem yang sangat besar. Perbedaan yang paling prinsip dari empat jenis beban diatas, selain dari daya yang digunakan dan juga waktu pembebanannya.

Pemakaian daya pada beban rumah tangga akan lebih dominan pada pagi dan malam hari, sedangkan pada beban komersil lebih dominan pada siang dan sore hari. Pemakaian daya pada industri akan lebih merata, karena banyak industri yang bekerja siang-malam. Maka dilihat dari sini, jelas pemakaian daya pada industri akan lebih menguntungkan karena kurva bebannya akan lebih merata. Sedangkan pada beban fasilitas umum lebih dominan pada siang dan malam hari. Beberapa daerah operasi tenaga listrik memberikan ciri tersendiri, misalnya daerah wisata, pelanggan bisnis mempengaruhi penjualan $\mathrm{kWh}$ walaupun jumlah 
pelanggan bisnis jauh lebih kecil dibanding dengan pelanggan rumah tangga [1].

\section{Perkiraan Energi Listrik}

Perkiraan energi listrik adalah suatu cara yang digunakan untuk mengukur atau memperkirakan kejadian dimasa yang akan datang. Perkiraan dapat dilakukan secara kualitatif maupun secara kuantitatif. Perkiraan dengan metode kualitatif adalah perkiraan yang didasarkan pada pendapat dari yang melakukan perkiraan sedangkan perkiraan kuantitatif adalah perkiraan yang menggunakan metode statistik. Berkaitan dengan hal tersebut, maka dalam perkiraan dikenal istilah prediksi dan perkiraan. Perkiraan didefinisikan sebagai proses perkiraan suatu variabel atau kejadian dimasa yang akan datang dengan berdasarkan data atau variabel yang telah terjadi sebelumnya. Data masa lampau tersebut secara sistematik digabungkan dengan menggunakan suatu metode tertentu dan diolah untuk mendapatkan perkiraan dimasa yang akan datang. Prediksi didefinisikan sebagai suatu proses perkiraan variabel atau kejadian dimasa yang akan datang dengan lebih mendasarkan pada pertimbangan subyektif/pendapat dari data kejadian yang telah terjadi dimasa lalu. Dalam proses prediksi ini, perkiraan yang baik sangat tergantung dari kemampuan, pengalaman dan kepekaan dari orang yang bersangkutan [2].

Berdasarkan jangka waktunya permalan dapat dikategorikan menjadi tiga kategori, yaitu [3]:

a. Prakiraan Jangka Panjang

Pada perencanaan sistem distribusi jangka panjang biasanya termasuk (tahun horison) dua belas tahun atau lebih sebelum saat sekarang: jangka waktu ini lebih besar untuk mempelajari transmisi atau pembangkitan utama. Kecuali diperkirakan pertumbuhan sangat sedikit, instalasi yang ada sedikit pengaruhnya dalam pengambilan keputusan. Sering kali keputusan diambil dengan bantuan studi standarisasi jaringan, termasuk model biaya.

b. Prakiraan Jangka Menengah

Jangka waktu untuk perencanaan jangka menengah ini antara tiga tahun sampai dua belas tahun, kebanyakan metode ekonomi untuk mengembangkan jaringan telah termasuk dalam parameter-parameter pada jangka panjang yang membahas pengembangan sistem dengan caracara lebih umum.

c. Prakiraan Jangka Pendek

Prakiraan jangka pendek atau rencana taktis memerlukan periode satu sampai tiga tahun dimuka dan biasanya hanya merupakan pelaksanaan hasil studi jangka panjang.

\section{Logika Fuzzy}

Logika fuzzy pertama kali diperkenalkan oleh Lotfi Zadeh pada tahun 1965, sebagai suatu cara matematis untuk menyatakan keadaan yang tidak menentu (samar) dalam kehidupan sehari-hari.

Logika fuzzy ini didasarkan pada teori fuzzy set yang merupakan perkembangan dari teori himpunan klasik. Logika fuzzy adalah suatu cara untuk memetakan suatu ruang masukan ke dalam suatu ruang keluaran. Fuzzy dapat juga disebut samar, kabur, ataupun tidak jelas. Pada logika fuzzy, suatu hal dapat memenuhi lebih dari satu kategori yang memiliki tingkat derajat keanggotan tertentu. Diperlukan suatu saluran tertentu yang harus dipenuhi dalam mengambil keputusan.

Dalam teori logika fuzzy dikenal himpunan fuzzy (fuzzy set), merupakan pengelompokan sesuatu berdasarkan variabel bahasa (linguistic variable), yang dinyatakan dalam fungsi keanggotaan (membership function). Didalam semesta pembicaraan (universe of discourse) $\mathrm{U}$, fungsi keanggotaan dari suatu himpunan fuzzy tersebut bernilai antara 0 sampai 1 [4].

\section{Variabel Linguistik}

Jika dalam aljabar setiap variabel diberi nilai berupa bilangan maka dalam himpunan fuzzy setiap variabel diberi nilai berupa kata-kata (words) atau kalimat (sentences). Variabel seperti ini disebut variabel linguistik. Himpunan dari nilai-nilai yang dapat diambil disebut dengan kumpulan istilah (term set) dari himpunan tersebut. Setiap nilai dalam kumpulan istilah adalah variabel fuzzy yang didefinisikan pada variabel dasar (base variable). Variabel dasar menyatakan Semesta Pembicaraan untuk semua variabel fuzzy dalam kumpulan istilah [4].

\section{Fungsi Keanggotaan}

Suatu kurva yang menunjukkan pemetaan titik titik input data ke dalam nilai keanggotaannya (sering juga disebut dengan derajat keanggotaan) yang memiliki interval antara 0 sampai 1 . Berikut merupakan fungsi keanggotaan yang dapat digunakan [4]:

1. Representasi Linear

a. Representasi Linear Naik

Kenaikan himpunan dimulai pada nilai domain yang memiliki derajat keanggotaan nil bergerak menuju kenilai domain yang memiliki derajat keanggotaan lebih tinggi, seperti pada Gambar 1.

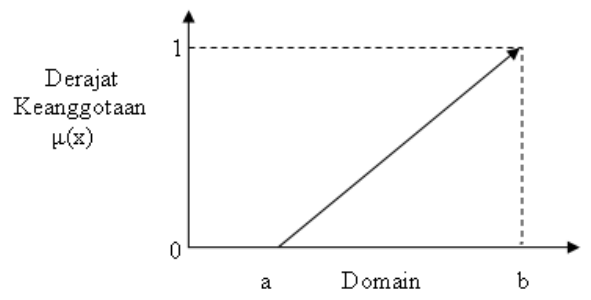

Gambar 1. Representasi Linear Naik 
fungsi keanggotaan :

$$
\mu[x]= \begin{cases}0 & ; x \geq b \\ (x-a) /(b-a) & ; a<x<b \\ 1 & ; x \leq a\end{cases}
$$

b. Representasi Linear Turun

Merupakan kebalikan dari linear naik, seperti pada Gambar 2.

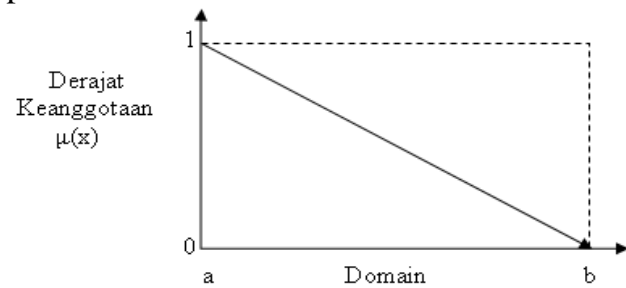

Gambar 2. Representasi Linear Turun

fungsi keanggotaan :

$$
\mu[\mathrm{x}]= \begin{cases}0 & ; \mathrm{x} \geq \mathrm{b} \\ (\mathrm{b}-\mathrm{x}) /(\mathrm{b}-\mathrm{a}) & ; \mathrm{a}<\mathrm{x}<\mathrm{b} \\ 1 & ; \mathrm{x} \leq \mathrm{a}\end{cases}
$$

2. Kurva Segitiga

Kurva segitiga pada dasarnya merupakan gabungan antara dua garis linear, seperti Gambar 3.

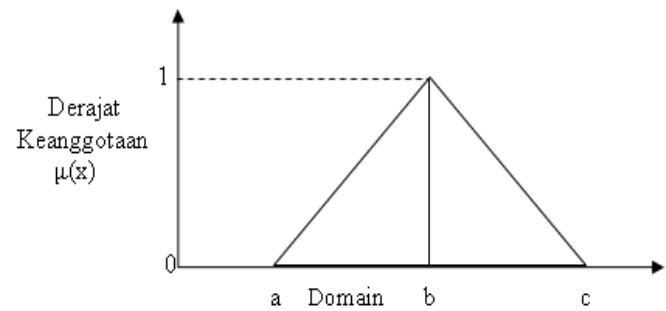

Gambar 3. Representasi Linear Turun

fungsi keanggotaan :

$\mu[\mathrm{x}]= \begin{cases}0 & ; \mathrm{x} \geq \mathrm{c} \text { atau } \mathrm{x} \leq \mathrm{a} \\ (\mathrm{b}-\mathrm{x}) /(\mathrm{b}-\mathrm{a}) & ; \mathrm{a}<\mathrm{x}<\mathrm{b} \\ 1 & ; \mathrm{b}<\mathrm{x}<\mathrm{c}\end{cases}$

3. Kurva Trapesium

Kurva Trapesium pada dasarnya seperti bentuk segitiga, hanya saja ada beberapa titik yang memiliki nilai keanggotaan satu, seperti pada Gambar 4

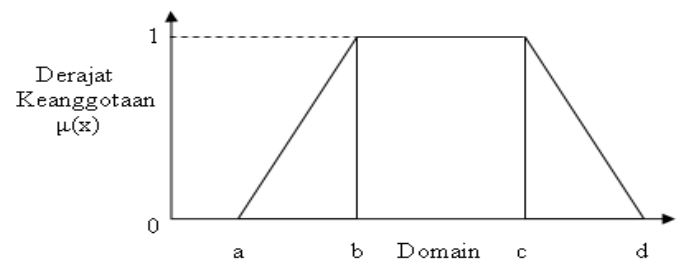

Gambar 4. Kurva Trapesium fungsi keanggotaan :

$\mu[\mathrm{x}]= \begin{cases}0 & ; \mathrm{x} \geq \mathrm{b} \\ (\mathrm{x}-\mathrm{a}) /(\mathrm{b}-\mathrm{a}) & ; \mathrm{a}<\mathrm{x}<\mathrm{b} \\ (\mathrm{d}-\mathrm{x}) /(\mathrm{d}-\mathrm{c}) & ; \mathrm{c}<\mathrm{x}<\mathrm{d} \\ 1 & ; \mathrm{b} \leq \mathrm{x} \leq \mathrm{c}\end{cases}$

4. Kurva Bahu

Daerah yang terletak ditengah - tengah satu variabel yang dipresentasikan dalam bentuk segitiga, pada sisi kanan dan kirinya akan naik dan turun. Tetapi terkadang salah satu sisi variabel tersebut tidak mengalami perubahan. Himpunan fuzzy bahu digunakan untuk mengakhiri variabel suatu daerah fuzzy, seperti pada Gambar 5.

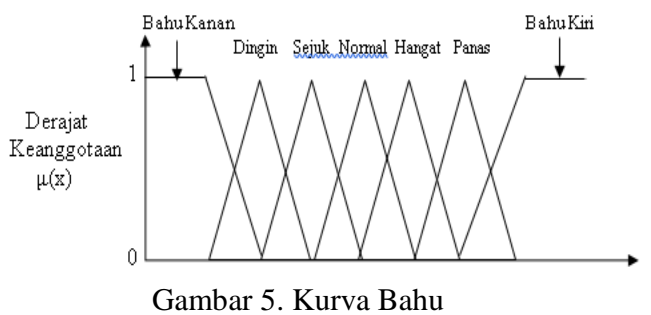

\section{Fuzzy Inference System (FIS) Mamdani}

Sistem Inference Fuzzy (Fuzzy inference system) adalah sistem yang dapat melakukan penalaran dengan prinsip serupa seperti manusia melakukan penalaran dengan nalurinya. Terdapat beberapa jenis FIS yang dikenal yaitu Mamdani, Sugeno dan Tsukamoto. FIS yang paling mudah dimengerti, karena paling sesuai dengan naluri manusia adalah FIS Mamdani. Metoda Mamdani dikenal juga sebagai metoda Min-Max yang diperkenalkan oleh Ebrahim Mamdani pada tahun 1975. FIS tersebut bekerja berdasarkan kaidah-kaidah linguistik dan memiliki algoritma fuzzy yang menyediakan sebuah aproksimasi untuk dimasuki analisa matematik. Salah satu metode evaluasi rule yang banyak dipakai adalah Inference Min-Max. Dalam inference "Min-Max", solusi himpunan fuzzy diperoleh dengan mengambil nilai maksimum aturan, kemudian digunakan untuk memodifikasi daerah fuzzy dan mengaplikasikannya ke output. Secara umum dapat dituliskan [4]:

$\mu_{\mathrm{sf}}\left(\mathrm{x}_{\mathrm{i}}\right)=\max \left(\mu_{\mathrm{sf}}\left(\mathrm{x}_{\mathrm{i}}\right), \mu_{\mathrm{kf}}\left(\mathrm{x}_{\mathrm{i}}\right)\right)$

Keterangan :

$\mu_{\mathrm{sf}}\left(\mathrm{x}_{\mathrm{i}}\right)=$ nilai keanggotaan solusi fuzzy sampai aturan ke- $i$

$\mu_{\mathrm{kf}}\left(\mathrm{x}_{\mathrm{i}}\right)=$ nilai keanggotaan konsekuen fuzzy sampai aturan ke- $i$

\section{Tahapan Operasional Logika Fuzzy}

Dalam sistem kendali logika fuzzy, terdapat beberapa tahapan operasional yang meliputi [5] : 
a. Fuzzyfikasi

Proses fuzzyfikasi ini berfungsi merubah masukan crisp menjadi masukan fuzzy. Masukan crisp dari sistem perlu diubah ke bentuk derajat keanggotaan fuzzy agar dapat diolah lebih lanjut dan setiap masukan dari sistem harus dapat terwakilkan pada himpunan keanggotaan fuzzy. Dalam fuzzyfikasi semesta masukan dibagi menjadi beberapa himpunan yang lebih kecil dengan fungsi keanggotaan.

b. Evaluasi aturan (rule)

Dalam langkah kedua proses logika fuzzy, dinamakan evaluasi aturan (rule). Proses fuzzy menggunakan aturan linguistik untuk menentukan aksi kendali apa yang harus dilakukan dalam merespon nilai masukan yang diberikan. Evaluasi rule juga mengacu pada fuzzy inference. Sistem Inferensi Fuzzy (Fuzzy Inference System /FIS) disebut juga Fuzzy Inference Engine adalah sistem yang dapat melakukan penalaran dengan prinsip serupa seperti manusia melakukan penalaran dengan nalurinya. FIS ini mengaplikasikan aturan pada masukan fuzzy yang dihasilkan dalam proses fuzzyfikasi, kemudian mengevaluasi tiap aturan dengan masukan yang dihasilkan dari proses fuzzyfikasi.

c. Defuzzyfikasi

Defuzzifikasi merupakan proses pemetaan himpunan fuzzy ke himpunan tegas (crisp).

Proses ini merupakan kebalikan dari proses fuzzyfikasi. Metode dalam melakukan defuzzyfikasi antara lain [6] :

1. Centroid method

Metode ini mengambil titik pusat daerah fuzzy sebagai solusi crisp. Secara umum dapat dirumuskan :

$\mathrm{z} *=\frac{\sum_{j=1}^{n} z_{j} \mu\left(z_{j}\right)}{\sum_{j=1}^{n} \mu\left(z_{j}\right)}$

2. Metode Bisektor

Metode ini solusi crisp diperoleh dengan cara mengambil nilai pada domain fuzzy yang memiliki nilai keanggotaan setengah dari jumlah total nilai keanggotaan pada daerah fuzzy.

3. Metode Mean of Maximum (MOM)

Metode ini mengambil nilai rata-rata domain yang memiliki nilai keanggotaan maksimum untuk memperoleh solusi crispnya.

4. Metode Largest of Maximum (LOM)

Pada metode ini, solusi crisp diperoleh dengan cara mengambil nilai tersebar dari domain yang memiliki nilai keanggotaan maksimum.
5. Metode Smallest of Maximum (SOM)

Pada metode ini, solusi crisp diperoleh dengan cara mengambil nilai terkecil dari domain yang memiliki nilai keanggotaan maksimum.

\section{Mean Absolute Percentage Error (MAPE)}

Metode ini melakukan perhitungan menggunakan perbedaan antara data asli dan data hasil prakiraan. Perbedaan tersebut diabsolutkan, kemudian dihitung dalam bentuk persentase terhadap data asli. Hasil persentase tersebut kemudian didapatkan nilai mean-nya. Suatu model memiliki kinerja sangat bagus jika nilai MAPE berada dibawah $10 \%$, dan berada diantara $10 \%$ dan $20 \%$ [7].

Adapun rumusan untuk menghitung kesalahan ini adalah :

Kesalahan $=\frac{\mid \text { actual }- \text { forecast } \mid}{\text { actual }} \times 100 \%$

Sedangkan untuk menghitung Mean Absolute

Percentage Error (MAPE) adalah [7]:

MAPE $=\frac{\sum_{i=1}^{n}\left|\frac{X_{i}-F_{i}}{x_{i}} \times 100\right|}{n}$

\section{Kependudukan}

Dalam jangka waktu 7 tahun (2010 - 2017), kepadatan penduduk meningkat seiring dengan naiknya jumlah penduduk. Penyebaran penduduk disetiap kecamatan belum merata, menurut data Badan Pusat Statistik (BPS), laju pertumbuhan penduduk Kota Dumai dari tahun 2010 - 2017 adalah sebesar 2,23\% [8] seperti pada Tabel 1.

Tabel 1. Jumlah Penduduk Kota Dumai Tahun 2010-2017

\begin{tabular}{cccc}
\hline Tahun & $\begin{array}{c}\text { Laki-laki } \\
\text { (Jiwa) }\end{array}$ & $\begin{array}{c}\text { Perempuan } \\
\text { (Jiwa) }\end{array}$ & $\begin{array}{c}\text { Jumlah } \\
\text { (Jiwa) }\end{array}$ \\
\hline 2010 & 130.910 & 122.268 & 253.178 \\
2011 & 133.645 & 126.268 & 259.913 \\
2012 & 137.715 & 130.307 & 268.022 \\
2013 & 140.776 & 133.313 & 274.089 \\
2014 & 143.900 & 136.209 & 280.109 \\
2015 & 146.792 & 139.175 & 285.967 \\
2016 & 149.791 & 142.117 & 291.908 \\
2017 & 152.731 & 144.907 & 297.638 \\
\hline
\end{tabular}

\section{Perekonomian}

Pertumbuhan ekonomi merupakan salah satu instrumen untuk mengevaluasi pembangunan ekonomi. Pertumbuhan ekonomi yang tinggi diperlukan terutama oleh daerah yang berkembang untuk mencapai target-target pembangunan ekonomi. Perekonomian Kota Dumai didominasi oleh empat sektor yakni, sektor bangunan, perdagangan, angkutan dan sektor jasa. Secara komulatif, empat sektor tersebut telah merangkum persentase sebesar 83,84 \% dari Produk Domestik Regional Bruto (PDRB) Kota Dumai. Pada tahun 2016 pertumbuhan Kota Dumai kembali meningkat, pertumbuhan paling tinggi terjadi pada tahun 2017 sebesar 4,45 \%. 
pertumbuhan ekonomi tertinggi dicapai oleh kategori jasa lainnya sebesar 8,05 \%, pada kategori pertambangan dan penggalian dan jasa keuangan dan asuransi mencatat pertumbahan yang negatif [8].

Adapun kategori-kategori lainnya berturut-turut mencatat pertumbuhan yang positif, diantaranya kategori pertanian, kehutanan, dan perikanan sebesar $3,34 \%$, kategori industri pengolahan sebesar 5,34\%, kategori pengadaan listrik dan gas sebesar 1,04\%, kategori pengadaan air, pengelolaan sampah, limbah dan daur ulang sebesar 4,60\%, kategori konstruksi $4,19 \%$, kategori perdagangan besar dan eceran, reparasi mobil dan sepeda motor $2,84 \%$, kategori transportasi dan perdagangan sebesar 5,33\%, kategori penyediaan akomodasi dan makan minum mencatat sebesar $6,30 \%$, kategori informasi dan komunikasi sebesar 5,47 \%, kategori real estat 3,43 $\%$, kategori jasa perusahaan sebesar 6,91\%, kategori administrasi pemerintahan, pertahanan dan jaminan sosial wajib sebesar $0,04 \%$, kategori jasa pendidikan sebesar 2,70 \%, dan kategori jasa kesehatan dan kegiatan sosial sebesar 5,49\% [8].

\section{Data Kelistrikan}

Kebijakan pemerintah dibidang kelistrikan ditujukan untuk meningkatkan kesejahteraan masyarakat dan mendorong kegiatan ekonomi khususnya sektor industri. Untuk mencapai sasaran tersebut diupayakan peningkatan daya terpasang, pembangkit tenaga listrik agar tersedia tenaga listrik dalam jumlah yang cukup dengan pelayanan yang baik, seperti pada Tabel 2.

Tabel 2. Banyaknya Jumlah Pelanggan

\begin{tabular}{ccccccc}
\hline \multirow{2}{*}{ No } & $\begin{array}{c}\text { Jenis } \\
\text { Pelanggan }\end{array}$ & 2013 & 2014 & 2015 & 2016 & 2017 \\
\hline \multirow{2}{*}{1} & Rumah & 54.873 & 59.766 & 64.162 & 68.432 & 83.866 \\
2 & Tangga & & & & & \\
2 & Bisnis & 6.945 & 7.234 & 7.462 & 7.755 & 8.518 \\
3 & Industri & 21 & 18 & 21 & 23 & 24 \\
4 & Umum & 1770 & 1696 & 2275 & 1878 & 2353 \\
\hline Jumlah & 63.609 & 68.714 & 73.920 & 78.088 & 94.761 \\
\hline
\end{tabular}

Tabel 3. Banyaknya Produksi Pelanggan (MWh)

\begin{tabular}{ccccccc}
\hline No & $\begin{array}{c}\text { Jenis } \\
\text { Pelanggan }\end{array}$ & 2013 & 2014 & 2015 & 2016 & 2017 \\
\hline 1 & Rumah & 118.054 & 130.982 & 139.624 & 151.504 & 157.704 \\
& Tangga & & & & & \\
2 & Bisnis & 55.852 & 62.394 & 66.430 & 70.188 & 72.041 \\
3 & Industri & 51.799 & 65.178 & 96.418 & 112.835 & 140.468 \\
4 & Umum & 14.892 & 21.866 & 21.360 & 22.597 & 24.806 \\
\hline & Jumlah & 250.512 & 281.472 & 323.833 & 356.349 & 393.459 \\
\hline
\end{tabular}

\section{HASIL DAN PEMBAHASAN}

\section{Pembentukan Himpunan Fuzzy}

Jumlah penduduk, jumlah pelanggan, dan rasio elektrifikasi dijadikan sebagai masukan perkiraan, sedangkan konsumsi energi dijadikan sebagai keluaran. FIS yang digunakan adalah tipe Mamdani. Masing-masing variabel tersebut memiliki himpunan variabel bahasanya (fuzzy set) yang direpresentasikan dalam bentuk fungsi keanggotaan (segitiga), seperti pada Gambar 6 dan Tabel 4.

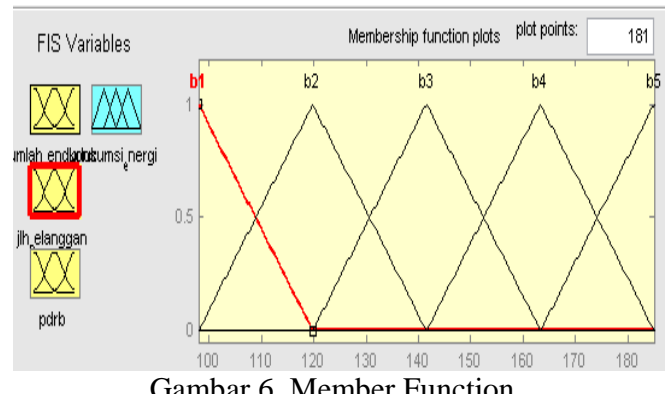

Gambar 6. Member Function

Tabel 4. Variabel Input Dan Himpunan Fuzzy

\begin{tabular}{|c|c|c|c|}
\hline & Variabel & $\begin{array}{l}\text { Himpunan } \\
\text { Fuzzy }\end{array}$ & Domain \\
\hline \multirow{4}{*}{ Input } & \multirow{4}{*}{$\begin{array}{c}\text { Jumlah } \\
\text { Penduduk }\end{array}$} & A1 & [280 - 320] \\
\hline & & $\mathrm{A} 2$ & [300 - 340] \\
\hline & & A3 & {$[320-360]$} \\
\hline & & A4 & [340 - 380] \\
\hline \multirow{5}{*}{ Input } & \multirow{5}{*}{$\begin{array}{c}\text { Jumlah } \\
\text { Pelanggan }\end{array}$} & B1 & {$[76,27-119,8]$} \\
\hline & & B2 & {$[98-141,5]$} \\
\hline & & B3 & $[119,8]-163,3]$ \\
\hline & & B4 & {$[141,5-185]$} \\
\hline & & B5 & {$[163,3-206,8]$} \\
\hline \multirow{4}{*}{ Input } & \multirow{4}{*}{ PDRB } & $\mathrm{C} 1$ & [2351 - 4263] \\
\hline & & $\mathrm{C} 2$ & [3308 - 5222] \\
\hline & & C3 & [4263 - 6177] \\
\hline & & $\mathrm{C} 4$ & [5222 - 7132] \\
\hline \multirow{5}{*}{ Output } & \multirow{5}{*}{$\begin{array}{c}\text { Konsumsi } \\
\text { Energi Listrik }\end{array}$} & D1 & {$[317,8-538,8]$} \\
\hline & & D2 & [428 - 649] \\
\hline & & D3 & {$[503,8-759.8]$} \\
\hline & & D4 & [649 - 870] \\
\hline & & D5 & [759.8 - 980.8] \\
\hline
\end{tabular}

\section{Fuzzyfikasi}

Fuzzyfikasi merupakan tahap awal dari proses inferensi. Fuzzyfikasi adalah proses merubah data yang telah diinput yang berupa data crisp (tegas) menjadi data dalam bentuk himpunan fuzzy dengan fungsi keanggotaan. Sebagai contoh ditentukan fungsi keanggotaan variabel jumlah penduduk berdasarkan persamaan 3, diperoleh fungsi keanggotaan sebagai berikut:

$$
\begin{aligned}
\mu \mathrm{A}_{1} & =(320-x) /(320-300) \\
& =(320-311,060) /(20) \\
& =8,94 / 20 \\
& =0,447
\end{aligned}
$$




$$
\begin{aligned}
\mu_{\mathrm{A} 2} & =(x-300) /(320-300) \\
& =(311,060-300) /(20) \\
& =11,060 / 20 \\
& =0,553
\end{aligned}
$$

\section{Aturan Fuzzy}

Dengan memperhatikan hubungan antara berbagai input terhadap output, maka dapat dibuat aturan-aturan (rule) untuk perkiraan tahun-tahun berikutnya dan diperoleh aturan sebanyak 80 aturan. Seperti pada Gambar 7.

1. If (jumlah__penduduk is a1) and (ilh_pelanggan is b1) and (pdrb is c1) then (Konsumsi_energi is D1) (1) 2. If (jumlah _penduduk is a1) and (jith pelanggan is b1) and (pdrb is $\mathrm{c}$ 2) then (Konsumsi energi is D1) (1) 3. If (jumlah penduduk is a1) and (ilh pelanggan is $b 1$ ) and ( $\mathrm{ndrb}$ is $\mathrm{c} 3$ ) then (konsumsi_energi is D2) (1)

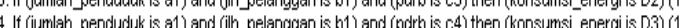
5 . It (jumlah pendudu is a1) and (ih nelangen is 2 2) and (pdrh is c1) then (

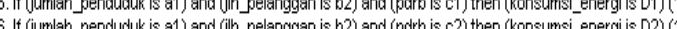
. If (f

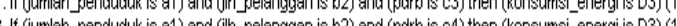
(t)

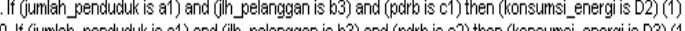

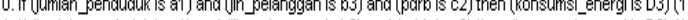
11. If (jumlah_penduduk is a1) and (jih_pelanggan is b3) and (pdrb is c3) then (konsumsi_energi is D3) (1)

\section{Gambar 7. Aturan Fuzzy}

\section{Aplikasi Fungsi Implikasi}

Setelah menentukan aturan fuzzy, tahapan berikutnya adalah menentukan aplikasi fungsi implikasi. Aplikasi fungsi implikasi pada metoda Mamdani digunakan fungsi MIN. Pada tahapan ini setiap derajat keanggotaan diproses kedalam 80 aturan fuzzy yang telah dibuat sebelumnya. Dengan nilai keanggotaan fuzzyfikasi yang telah didapat, maka $\alpha$-predikat (fire strength) dapat ditentukan dengan aturan [R1], [R2], [R5], [R6], [R22], [R25] dan [R26].

\section{Penegasan (Defuzzyfikasi)}

Pada tahap defuzzyfikasi ini data yang telah dirubah menjadi data fuzzy dioutputkan kembali menjadi data tegas (crisp). $\alpha$-predikat yang mempunyai nilai adalah aturan [R1], [R2], [R5], [R6], [R22], [R25] dan [R26], Sehingga diperoleh titik pusat daerah untuk konsumsi energi listrik pada tahun 2019 adalah sebesar :

$$
\begin{aligned}
& z=\frac{358,208+526,421}{2} \\
& =\frac{914,977}{2} \\
& =457,488
\end{aligned}
$$

Maka hasil konsumsi energi listrik yang diperoleh dengan metode centroid adalah 457,488 GWh. Pada tahun 2019 konsumsi energi listrik yang didapatkan menggunakan Matlab adalah sebesar 514 GWh, seperti pada Gambar 8.

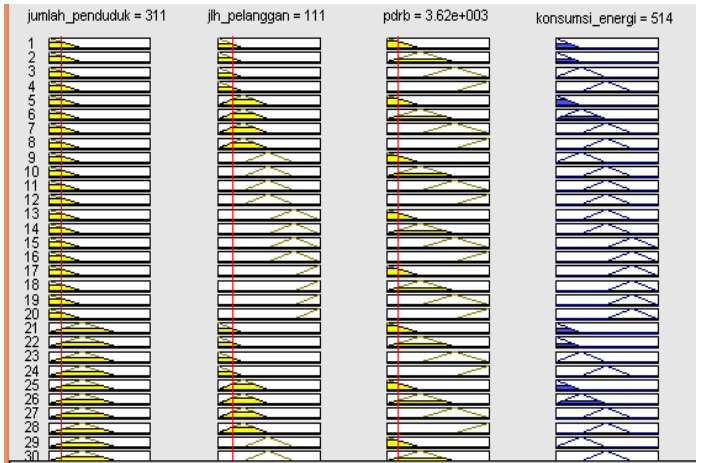

Gambar 8. Konsumsi Energi Listrik Tahun 2019 dengan Menggunakan Matlab

\section{Peramalan Hasil Konsumsi Energi Listrik}

Ramalan konsumsi energi listrik dengan fuzzy Mamdani untuk kemudahan dapat dilakukan dengan bantuan software MATLAB R2007b, rancangan sistem inferensi fuzzy tersebut dikerjakan pada Fuzzy Logic Toolbox. Berdasarkan contoh perhitungan pada sub bab sebelumnya, dilakukan hal yang sama untuk peramalan data lainnya. Seperti pada Tabel 5.

Tabel 5. Hasil Ramalan Konsumsi Energi Listrik Tahun 2018 - 2025 Menggunakan Fuzzy Logic

\begin{tabular}{ccc}
\hline No & Tahun & $\begin{array}{c}\text { Perkiraan Logika Fuzzy } \\
(\mathrm{GWh})\end{array}$ \\
\hline 1 & 2018 & 466 \\
2 & 2019 & 514 \\
3 & 2020 & 534 \\
4 & 2021 & 591 \\
5 & 2022 & 644 \\
6 & 2023 & 707 \\
7 & 2024 & 766 \\
8 & 2025 & 792 \\
\hline
\end{tabular}

Data yang didapat dari PLN digunakan sebagai pembanding terhadap perkiraan yang dihasilkan oleh logika fuzzy. Berikut ini hasil perkiraan konsumsi energi listrik yang dihasilkan oleh logika fuzzy dengan rata-rata pertumbuhan konsumsi energi listrik sebesar 7,16\% yang dibandingkan terhadap perkiraan yang dilakukan oleh PT. PLN Area Dumai, seperti pada Tabel 6.

Tabel 6. Perbandingan Perkiraan Konsumsi Energi Listrik

\begin{tabular}{cccc}
\hline Tahun & $\begin{array}{c}\text { Perkiraan PLN } \\
(\text { GWh })\end{array}$ & $\begin{array}{c}\text { Perkiraan } \\
\text { Logika Fuzzy } \\
(\text { GWh })\end{array}$ & Kesalahan $(\%)$ \\
\hline 2018 & 433 & 466 & 7,6 \\
2019 & 478 & 514 & 7,5 \\
2020 & 523 & 534 & 2,1 \\
2021 & 582 & 591 & 1,5 \\
2022 & 643 & 644 & 0,15 \\
2023 & 710 & 707 & 0,42 \\
2024 & 784 & 766 & 2,3 \\
2025 & 866 & 792 & 8,5 \\
\hline
\end{tabular}


Pada Tabel 6 hasil perkiraan antara PT. PLN Area Dumai dengan logika fuzzy tidak jauh berbeda. Nilai kesalahan rata-rata yang didapat sebesar 3,76 \% yang berarti perkiraan menggunakan fuzzy sangat bagus karena nilai MAPE atau kesalahan dibawah 10 $\%$.

\section{KESIMPULAN}

1. Berdasarkan hasil peramalan konsumsi energi listrik di Kota Dumai pada tahun 2025 dengan logika fuzzy diperoleh hasil ramalan sebesar 792 GWh, sementara konsumsi energi listrik pada tahun 2025 menurut peramalan PT. PLN Area Dumai sebesar 866 GWh.

2. Berdasarkan hasil peramalan menggunakan fuzzy logic didapatkan rata-rata pertumbuhan konsumsi energi listrik setiap tahunnya sebesar $7,16 \%$.

3. Hasil perkiraan antara PT. PLN Area Dumai dengan logika fuzzy tidak jauh berbeda. Nilai rata - rata kesalahan yang diperoleh sebesar 3,76 $\%$, diketahui bahwa data perkiraan konsumsi energi listrik yang dihasilkan oleh PT. PLN hanya digunakan sebagai data pembanding, karena nilai konsumsi energi listrik untuk 7 tahun ke depan belum dapat dipastikan.

\section{DAFTAR PUSTAKA}

[1] M. B. Fadillah, Analisis Prakiraan Kebutuhan Energi Listrik Tahun 2015-2024 Wilayah PLN Kota Pekanbaru Dengan Metode Gabungan, Jom FTEKNIK, vol. 2, no. 2, pp. 1-10, 2015.

[2] M. H. dkk Albab, Proyeksi Kebutuhan Energi Listrik APJ Pekalongan Tahun 2014-2018 Dengan Metode Logika Fuzzy, Transient, vol. 4, no. 3, pp. 1-6, 2015.

[3] A. Pabla, Sistem Distribusi Daya Listrik, Ahli Bahasa Abdul Hadi. Jakarta: Erlangga, 1994.

[4] S. Kusumadewi, Analisis dan Desain Sistem Fuzzy Menggunakan Tool Box Matlab. Yogyakarta: Graha Ilmu, 2002.

[5] H. D. Laksono dan H. Effendi, Aplikasi Logika Fuzzy Pada Perkiraan Kebutuhan Energi Listrik Jangka Panjang Di Provinsi Sumatera Barat Sampai Tahun 2018, Teknol. Inf. Pendidik., vol. 3, no. 1, pp. 42-53, 2011.

[6] L. Maulida, Implementasi Logika Fuzzy Mamdani Untuk Peramalan Beban Listrik Jangka Pendek Perusahaan Listrik Negara (PLN) Rayon Banda Aceh, Universitas Syaih Kuala, 2016.

[7] M. Z. A. Zainun, N. Y dan Majid, Low Cost House Demand Predictor, Universitas Teknologi Malaysia, 2003.

[8] BPS Dumai, Kota Dumai Dalam Angka 2017. BPS Kota Dumai, 2017. 